\title{
NOS RASTROS DA MEMÓRIA: UMA REVISITAÇÃO DA GUERRA DE CANUDOS PELO OLHAR DE VARGAS LLOSA
}

\author{
Solange Regina da Silva ${ }^{1}$ \\ Isis de Paula Oliveira de Albuquerque ${ }^{2}$ \\ Brenda Carlos de Andrade 3
}

\begin{abstract}
Resumo: Este artigo pretende analisar o panorama de como se desenvolveram as relações entre história e literatura nas narrativas do século XX. Com esse intuito, foi tomado como referencial no romance A guerra do fim do mundo (1981), de Mario Vargas Llosa. Neste livro encontramse algumas expressões que permitem certa reconstrução do passado de forma ficcional realista através do resgate da memória oral, evidenciada pelas descrições das personagens como pano de fundo, o que põe em destaque o caráter de historicidade da obra. De modo a fundamentar a nossa reflexão, recorreremos aos contributos de: Lukács (2011), Mircea Eliade (2011), Jaques Le Goff (1990), Beatriz Sarlo (2010), Antônio Candido (2006), entre outros. Em suma, esse texto visa contribuir com estudos que reflitam e reativem a importância de se discutir o caráter significativo dos romances históricos na Literatura Latino-Americana.
\end{abstract}

Palavras-chave: Romance histórico. Memória. A guerra do fim do mundo. Vargas Llosa.

\section{INTO MEMORY TRACES: A NEW LOOK OF CANUDOS WAR BY THE EYES OF VARGAS LLOSA}

Abstract: This article aims to analyze the outlook of how the relations between history and literature are developed into the narratives of 20th century. To achieve this goal, it was taken as reference the novel The War of the End of the World (1981), by Mario Vargas Llosa. In this book it is possible to find some context that allowing the reconstruction of the past in a realistic fictional way by rescuing oral memory evidenced through specific descriptions of the characters as background, that evidences the historical style of the book. To fundament our reflections, we utilized the theoretical contribution of Lukács (2011), Mircea Eliade (2011), Jaques Le Goff (1990), Beatriz Sarlo (2010), Antônio Candido (2006), and others. In short, this paper aims to contribute with studies that reflect and reactivate the importance of discussing the significant aspect of historical novels into Latin-American Literature.

Keywords: Historic novel. Memory. The war of the end of the world. Vargas Llosa.

\section{EN LAS HUELLAS DE LA MEMORIA: UNA REVISITACIÓN DE LA GUERRA DEL FIN DEL MUNDO DE VARGAS LLOSA}

Resumen: Este artículo pretende analizar el panorama de cómo se desarrollaron las relaciones entre historia y literatura en las narrativas del siglo XX. Para ello, se ha tomado como referencia en la novela La guerra del fin del mundo (1981), de Mario Vargas Llosa. En ella, se encuentran algunas expresiones que permiten una cierta reconstrucción del pasado de manera realista ficcional a través del rescate de la memoria oral evidenciada por las descripciones de los personajes como trasfondo, lo que resalta el carácter de la historicidad de la obra. Para sostener

\footnotetext{
${ }^{1}$ Mestranda do Programa de Pós-Graduação em Letras da Universidade Federal de Pernambuco (PPGL/ UFPE). Bolsista CAPES.

${ }^{2}$ Mestranda do Programa de Pós-Graduação em Letras da Universidade Federal de Pernambuco (PPGL/ UFPE). Bolsista CAPES.

${ }^{3}$ Professora Adjunta da Universidade Federal Rural de Pernambuco (UFRPE) - Departamento de Letras e Ciências Humanas. Professora do Programa de Pós-Graduação em Letras da Universidade Federal de Pernambuco (PPGL/ UFPE).
} 
nuestra reflexión, utilizamos los aportes de: Lukács (2011), Mircea Eliade (2011), Jaques Le Goff (1990), Beatriz Sarlo (2010), Antônio Candido (2006), entre otros. En definitiva, este texto pretende contribuir a estudios que reflejen y reactiven la importancia de discutir el carácter significativo de las novelas históricas en la Literatura latinoamericana.

Palabras-clave: Novela histórica. Memoria. La guerra del fin del mundo. Vargas Llosa.

\section{Alguns pressupostos}

O presente artigo visa averiguar de que modo os acontecimentos históricos dos conflitos ocorridos em Canudos, no final do século XIX, presentes na obra A guerra do fim do mundo (1981), do escritor Mario Vargas Llosa, permitem certa reconstrução do passado de forma ficcional realista. Na obra, esse resgate é feito através da memória oral evidenciada pelas descrições das personagens como pano de fundo, o que põe em destaque o caráter de historicidade da obra. $\mathrm{O}$ autor, além do trabalho de pesquisa de fontes históricas, também tem o cuidado de trazer outras fontes que não são oficiais nem escritas, como a memória oral. Para o estudo aqui pretendido, analisamos o contexto histórico da guerra a partir dos relatos das personagens, a fim de identificar possíveis vestígios, ou seja, semelhanças e diferenças que contribuam para uma releitura do passado. Em seguida, reconhecemos, no sentido de reforçar a validade dessas fontes, a revisitação da história de Canudos no final do século XIX por meio da tradição oral, com foco na memória comunicativa expressa por um movimento popular, que é a comunidade de Canudos. Por fim, buscamos contribuir com estudos que reflitam e reativem a importância de discutir o caráter significativo dos romances históricos da Literatura Latino-Americana.

Sabe-se que a relação entre história e literatura vem sendo estabelecida desde muito tempo. Esses dois campos, já foram tratados como áreas próximas e distantes. Desde Aristóteles o papel dos dois ofícios — o do historiador e o do poeta — vem sendo discutido. O filósofo inaugurou os debates com o seu livro Poética, no qual postulava que caberia à história a narração dos fatos que realmente aconteceram e à literatura, a representação dos episódios. A partir disso, houve um longo percurso dentro desse terreno, que envolve as relações que essas duas áreas construíram entre si. Foi durante o século XIX que se desenvolveu um olhar para o papel do historiador e para a importância do documento, o que configurava aos estudos históricos uma posição de verdade. Nesse período, as experiências sociais cotidianas tornaram-se objetos de estudo da história, quando o historiador tenta narrar os fatos realmente como aconteceram.

Já no século XX; houve uma tentativa de renovação dessa disciplina. Podemos comprovar isso observando as ideias desenvolvidas por Hayden White (2001), o qual 
afirmou que os modos de expor a narrativa para a história e para a ficção eram semelhantes. Acrescenta-se a isso que nessa época também havia uma crescente disposição em desenvolver um conhecimento interdisciplinar, aproximando a crítica literária do conhecimento histórico. Sendo assim, literatura e história, lado a lado, cada uma com seus métodos, assemelham-se quando procuram elaborar discursos explicativos sobre os seus objetos. É verdade que, nos dois casos, a marca do historiador e do literato está impressa no que chamamos de "produto final", que são as obras produzidas.

A obra A guerra do fim do mundo, de Mario Vargas Llosa, cujo tema central é a Guerra de Canudos, apresenta-se como um exemplo de como a literatura pode contribuir para o conhecimento histórico. Além disso, o livro mostra que essa interdisciplinaridade tão questionada e debatida ao longo dos anos entre história e literatura também se faz presente num campo muito maior, que os estudos acadêmicos classificaram como Humanidades. Vargas Llosa, autor de ficções, escritor, romancista, jornalista e intelectual, afirmou em inúmeras entrevistas que A guerra do fim do mundo, a qual levou quatro anos para finalizar, foi sua melhor obra.

Uma das grandes façanhas do escritor peruano foi ter escolhido o evento da Guerra de Canudos principalmente por se tratar de um episódio tão importante para a história, além da forma como escreve o romance. A história do processo da escrita do livro começa por volta dos anos setenta, quando Vargas Llosa é convidado para escrever um roteiro de um filme sobre Canudos. Ainda que esse projeto não tenha sido materializado, Llosa se encanta com a obra de Euclides e decide escrever um romance ficcional. A obra reconta um evento histórico que já foi narrado outras vezes, agregando-lhe diferentes pontos de vistas. Sendo assim, A guerra do fim do mundo tornou-se um grande sucesso não só no Brasil como em outras partes do mundo.

Segundo Beatriz Sarlo (2010), o retorno ao passado nunca esteve tão presente. Desse modo, revisitar Canudos, cerca de oitenta anos depois do lançamento da obra $O s$ Sertões, fez com que Llosa trouxesse à tona esse marcante conflito armado, ressaltando suas particularidades. Essa reescrita também foi uma tentativa de mostrar aos leitores como esse tema é fundamental para entender a construção do Brasil e da América Latina. O romance de Llosa possui muitas diferenças em relação à obra euclidiana, principalmente se consideramos as personagens, pois o autor peruano dá voz aos marginalizados, utilizando uma estrutura e abordagem bem diferentes. Assim, reviver a Guerra de Canudos dentro da literatura aparece como uma elaboração de um espaço de 
construção de novas perspectivas e de reelaboração da obra de Euclides. Nesse caso, a obra produzida por Llosa, no século XX, de certa forma, apresenta-se como uma representação do que estava acontecendo na América Latina e, nesse aspecto, ela rompe barreiras culturais, espaciais e idiomáticas.

E foi a partir disso que traçamos os caminhos para a escrita deste trabalho, recorrendo a alguns teóricos que se debruçaram sobre esse tema, tais como: Lukács (2011), Mircea Eliade (2011), Jacques Le Goff (1990), Antonio Candido (2006), Beatriz Sarlo ( 2010), entre outros.

\section{História e Literatura: o romance histórico}

É pertinente comentar que tanto a história quanto a literatura são modos de explicar o presente, mas que também se movem pelo passado e pelo futuro e sempre utilizam diferentes estratégias para inserir nas narrativas os fatos e os aspectos sobre os quais se propõem a discutir. Esses dois campos foram amplamente analisados a partir do surgimento do que chamamos de romance histórico. Esse gênero teve seu surgimento com o escritor Walter Scott, como podemos observar nas palavras de Lukács:

O romance histórico scottiano é continuação direta do grande romance social realista do século XVIII. Os estudos de Scott sobre esses escritores - estudos que, do ponto de vista teórico, não são muito profundos em geral denotam um conhecimento muito intenso, muito pormenorizado dessa literatura. Mas sua criação, em relação à deles, significa algo inteiramente novo. Seus contemporâneos viram com clareza essa novidade. Púchkin escreve sobre ele: A influência de Walter Scott pode ser percebida em todos os terrenos da literatura de sua época. A nova escola dos historiadores franceses formou-se sob a influência da ideia do romancista scottiano. Ele lhes mostrou fontes inteiramente novas, até então desconhecidas, apesar da existência dos dramas históricos de Shakespeare e Goethe [...]. E Balzac ressalta, em sua crítica a A cartuxa de Parma, de Stendhal, os novos traços estéticos que o romance de Walter Scott introduziu na literatura épica: o amplo retrato dos costumes e das circunstâncias dos acontecimentos, o caráter dramático da ação e, em estreita relação com isso, o novo e importante papel do diálogo no romance. (LUKÁCS, 2011, p.47)

O romance histórico de Scott relatava os grandes acontecimentos históricos e provocava o olhar dos leitores para os protagonistas dos eventos históricos. Tratava-se de figurar de modo vivo as motivações sociais e humanas a partir das quais os homens pensavam e agiam, tentando, de certa forma, retratar como isso ocorreu na realidade histórica.

Os campos da história e da literatura que ora aparecem como próximos, ora distantes, baseiam-se na necessidade de distinguir o real do ficcional. Ou seja, enquanto 
a Literatura passou a ser um sinônimo de subjetividade, a História passou a buscar cada vez mais um caráter objetivo. Esse seria um dos temas fundamentais que permeiam as discussões entre essas duas áreas. No campo ficcional, o escritor pode e tem a liberdade de criar um contexto e de usar de diferentes situações para agradar ao leitor. Já no âmbito histórico, há um compromisso com os fatos, o que não permite inventar situações ou personagens. O historiador reconstrói os acontecimentos das histórias vividas, dando informações aos leitores e deixando claro que existem possibilidades de leituras, com diversas formas e escritas que se complementam entre si. Essa questão talvez seja o ponto que se apresenta como diferença principal entre as duas áreas, mesmo que em determinados momentos elas se aproximem, sobretudo com relação às técnicas e à textualidade, e, com isso, acabem revolucionando as formas acadêmicas tradicionais.

O romance histórico, considerado uma narrativa híbrida de história e ficção, teve seu início no século XIX com Walter Scott. Este autor, no ano de 1814, publicou um romance histórico intitulado Waverley, o qual, desde então, expandiu-se pelas literaturas ocidentais tendo um grande êxito entre os leitores. Segundo Lukács (2011), o que faltava ao romance histórico anterior ao de Walter Scott é o elemento especificamente histórico, o fato de a particularidade dos homens ativos derivar da especificidade histórica de seu tempo. Entendemos, assim, que os historiadores têm um compromisso com os fatos retratados, que conferem certa verossimilhança dentro da narrativa e que dizem respeito ao passado. Apesar das narrativas de caráter híbrido já existirem antes de Scott, o esquema criado por ele fixou algumas bases:

O esquema básico do romance histórico criado por Scott, que acabou por se impor, obedecia a dois princípios básicos. O primeiro deles é que a ação ocorre num passado anterior ao presente do escritor, tendo como pano de fundo um ambiente histórico rigorosamente reconstruído, onde figuras históricas ajudam a fixar a época. Sobre esse pano de fundo, situa-se uma trama fictícia, com personagens e fatos inventados pelo autor. Uma importante preocupação do romance histórico romântico era conseguir um equilíbrio entre a fantasia e a realidade, onde os jogos inventivos do escritor, aplicados a dados históricos produzissem composições que oferecessem aos leitores, ao mesmo tempo ilusão de realismo e oportunidade de escapar de uma realidade não satisfatória (ESTEVES, 2008, p.58).

Tendo em vista que o romance histórico durante o século XIX não teve tantas mudanças, já que a maioria dos escritores continuou seguindo o esquema dos românticos, com a diferença apenas na maneira como são descritos os ambientes, utilizando mais detalhes. Vale salientar que o conceito de história scottiano se fundava 
mais na ação individual que na ação coletiva. Lukács, que foi o principal estudioso da obra de Walter Scott, baseou muito da sua concepção do romance histórico a partir do estudo da produção desse autor. O teórico húngaro publicou uma obra em 1937, na qual ele argumenta que os grandes momentos históricos de crise favorecem o surgimento de uma reflexão sobre o curso e o sentido que a história tomava.

Segundo Esteves (2008), o romance histórico passou por algumas crises de identidade, e isso seria devido a sua essência híbrida. Assim, conforme mudam as concepções de romance e de suas relações com a sociedade, também muda o que é entendido como romance histórico. $\mathrm{O}$ autor também pontua que, aliado a essas novas compreensões, observa-se uma mudança epistemológica do discurso histórico ao longo do tempo.

Além disso, quando o romance histórico surgiu, o Romantismo ainda estava em curso e tratava-se de uma época em que diferentes nacionalidades estavam sendo definidas. Sendo assim, o romance histórico também passou a desempenhar um papel importante na construção das nacionalidades e identidades que almejavam se afirmar. $\mathrm{O}$ despertar do sentimento nacional e, consequentemente, da sensibilidade e do entendimento para a história nacional ocorre na Europa e na América Latina em conjunto com o surgimento do novo humanismo e de um novo conceito de progresso.

Em relação ao romance histórico, não se trata do relatar contínuo de grandes acontecimentos históricos, mas do despertar ficcional dos homens que o protagonizaram, como podemos comprovar no que aponta Lukács a seguir:

As rápidas e sucessivas reviravoltas produzidas nos acontecimentos intensificam a aceleração temporal diante da qual a percepção das mudanças como os fatos naturais não ocorre, fazendo com que os homens se vejam como sujeitos da história, em uma experiência sem precedentes de reconhecimento das multidões, nomeadas de "sentimento histórico". O que significa não só a percepção de que os destinos individuais estavam conectados com o universal, mas, sobretudo, a demanda por uma nova compreensão da história nacional e das suas correlações com o movimento internacional, isto é, com a história universal (LUKÁCS, 2011, p. 18).

O grande objetivo ficcional de Walter Scott ao figurar as crises e acontecimentos históricos da vida nacional é mostrar a grandeza humana que se desnuda em seus representantes, que são as figuras históricas, a partir da comoção de toda a vida da nação. Dessa maneira, entende-se que o que importa para o romance histórico é evidenciar, por meios ficcionais, a existência e o ser precisamente. 
O que chamamos de romance histórico carrega uma abertura para o recontar do passado e permite uma certa reconstrução do passado que pode possibilitar ao leitor uma nova percepção da sociedade e de seus costumes, mas, ao mesmo tempo, traz consigo marcas da época em que ele foi criado. Podemos dizer que não é uma tarefa fácil definir o caráter histórico de uma obra, pois esse tema é uma grande discussão entre os teóricos. Porém, apesar de nem todos os estudiosos estarem de acordo, seria importante ressaltar que talvez um dos pontos mais relevantes a se considerar seja tentar entender que existe um distanciamento temporal entre o acontecimento real e a obra ficcional.

Existem vários estilos de romance histórico que vão se relacionando com a Literatura e a História de diferentes formas. Muitas vezes, as fronteiras entre essas duas áreas são porosas, e o que é criado a partir dessa mistura é criticado por não se enquadrar totalmente nem em um campo, nem no outro. Quando interpretamos os fatos, vemos principalmente que o que era história e o que era literatura no século XIX não é o mesmo que hoje. Isso mostra que não se consegue encontrar uma visão fechada em relação ao gênero chamado de romance histórico.

Segundo Seymour Menton (1993), todo romance é histórico, pois, em maior ou menor grau capta o ambiente pessoal das suas personagens, até dos mais introspectivos. No que diz respeito ao século XX, aparecem diferentes manifestações do romance histórico na América Latina que são estudadas e muitas delas se distanciam um pouco da ideia que formulou Scott. Encontramos a partir daí uma ruptura com relação aos modelos do século XIX. O romance histórico, tal como foi concebido na sua origem, apresenta marcas que lhe são essenciais, como bem aponta Lukács (2011) em sua obra, como a necessidade de traçar grandes painéis históricos abarcando determinada época e um conjunto de acontecimentos, entre outras.

No caso da história como enredo, os procedimentos da escrita se organizam de acordo com a temporalidade cronológica de todos os episódios narrados. No romance histórico há o uso das personagens fictícias para fazer uma análise dos fatos históricos. O narrador muitas vezes se apresenta na terceira pessoa em uma tentativa de demostrar imparcialidade, sendo esta uma característica própria do discurso da história. Os autores também se valem dos dados históricos para conferir veracidade às narrativas, e, em determinados casos, algumas personagens históricas aparecem como pano de fundo na narrativa. 
A crítica e a historiografia literárias colocam a origem desse processo na obra $O$ reino deste mundo (1949), do cubano Alejo Carpentier, uma vez que a mesma já apresenta grande parte dos elementos que caracterizam o chamado novo romance histórico latino-americano, especialmente aquele produzido a partir dos anos setenta do século XX. Por isso, Carpentier é apontado por Menton como precursor do novo romance histórico latino-americano:

Sea 1949 [ano de publicação de El reino de este mundo, considerado por Menton como o primeiro novo romance histórico latino-americano], 1974 [ano de publicação de Yo el Supremo de Roa Bastos], 1975 [ano de publicação de Terranostra de Carlos Fuentes] o 1979 [ano de publicação de El arpa y la sombra e auge do crescimento do subgênero] el año oficial del nacimiento de la $\mathrm{NNH}$, no cabe ninguna duda de que fue engendrada principalmente por Alejo Carpentier con apoyo muy fuerte de Jorge Luis Borges, Carlos Fuentes y Augusto Roa Bastos (MENTON, 1993, p. 42).

Menton (1993) também atribui a Jorge Luis Borges grande importância nesse processo, vendo o escritor argentino como um grande inspirador do gênero. No final do século XX e começo do século XXI, mais ou menos na década de noventa, surge uma grande produção de obras cinematográficas de caráter épico, ao mesmo tempo em que aparece uma grande produção de obras nas prateleiras das livrarias dedicadas a esse tema, o que faz surgir alguns questionamentos: será que podemos falar de preocupação histórica? De onde surge isso? Na América, um fator importante para esse resgate histórico do passado é a comemoração dos quinhentos anos da conquista na América Latina, que traz marcas profundas que ficaram na história e na Europa. Há ainda uma grande revisitação da Segunda Guerra Mundial.

\section{Nas trincheiras da memória}

Ao longo da história, a memória se apresenta como uma ferramenta técnica, também conhecida como mnemotécnica, a qual, teoricamente, objetiva sistematizar registros memorialísticos, sejam eles individuais ou coletivos. É a partir de tais desdobramentos conceituais que o francês Pierre Nora (1993), em seu artigo "Entre memória e história: a problemática dos lugares", busca refletir a questão da necessidade moderna de escolher e selecionar lugares onde se possam "depositar" memórias e, com isso, faz uma crítica à posição da literatura em meio a tais divisões, das quais, a literatura é vista, também, como um lugar de memória.

Nesse sentido, não só os lugares físicos como, por exemplo, os arquivos públicos; as bibliotecas; os museus são dignos de captação dessas ditas memórias, mas 
também, os espaços narrativos - sejam eles da tradição oral ou escrita - garantem de forma retroalimentativa tanto a cristalização de lembranças quanto a sua transmissão para as futuras gerações de forma gradativa. O que coloca em xeque a questão divisória entre os conceitos de história e memória e suas relações com os textos literários, cujo arrimo se desdobre sobre o fator subjetivo da linguagem e transmite não aquilo que foi, mas sim aquilo que poderia ser dentro de inúmeras possibilidades de trabalhar com o ideário de verdade ou real.

Para Jaques Le Goff (1990), a História seria uma análise crítica do passado ou um estudo do presente a partir do passado, já a memória, um conhecimento do passado capitaneado pelo presente. Isto é, um conhecimento que "bebe" de lembranças individuais e por essa razão está sujeito a "jogos" de interesses e poder, que não necessariamente perpassam pelo crivo da pesquisa crítica. Daí o nosso interesse fundamental em se trabalhar com o objeto literário: o texto de ficção. Por ele não estar, meramente, condicionado aos anseios do que é ou não é real diante dos fatos históricos.

Concomitantemente, em relação à discussão historiográfica atual sobre a questão da memória, não se pode esquecer que, segundo Peter Burke (1992), as memórias são produtos de grupos sociais, por isso têm interesses ideológicos, políticos e sociais. É devido a isso que Burke chama a atenção para os estudos do sociólogo francês Maurice Halbwachs, que desenvolveu o famoso conceito de "estrutura social da memória". Conforme essa ideia, a memória é social e pode ser compartilhada, mas é preciso considerar que a elaboração da memória e as lembranças são ações completamente individuais e distintas. A memória traz, assim, uma representação do passado de um indivíduo, o qual está inserido em um contexto social, familiar e nacional.

Em termos gerais, para refletir a Literatura a partir da perspectiva da História Social, alguns autores enxergaram a possibilidade de historicizar a obra literária inserindo-a nos movimentos da sociedade que investigam e buscam suas intersecções para tentar entender a forma como as obras constroem ou representam a realidade social. A literatura como fenômeno estético, sendo também uma manifestação sociocultural, é utilizada pelo homem para expressar seus anseios e suas visões de mundo. A ficção constitui-se, desse modo, como uma possibilidade de registro do homem na sua historicidade. É essa característica que a tem transformado em objeto de pesquisa nas mãos de alguns historiadores. Nesse sentido, pode-se dizer que a Literatura registra aspectos do campo social no qual ela se insere e é também constituída a partir 
do mundo sociocultural. Ela é uma das formas de ler e interpretar os tempos e os espaços no mundo.

Desse modo, visto pela perspectiva do romance histórico, a obra A guerra do fim do mundo, de Vargas Llosa, é tomada, aqui, mais como uma possibilidade de reativação da nossa memória coletiva pelo veio da imaginação, que encontra relação direta com as páginas de história que contam o confronto entre um movimento popular de fundo sociorreligioso e o Exército da República no final do século XIX: a chamada "Guerra" de Canudos. Desde o prólogo, o autor do romance deixa claro os caminhos que o levaram a escrever a referida obra e destaca, sobretudo, a figura de Euclides da Cunha e o romance Os sertões (1902). Outro ponto importante dentro do prólogo é o fato de que Llosa traz à tona os espaços por onde passou - Rio de Janeiro; Salvador; sertão da Bahia; Sergipe - durante seu projeto de escrita. Por fim, relembra Canudos através da imagem atualizada do espaço e pelos objetos marcados pela história: “onde era Canudos havia um lago artificial, e suas margens estavam coalhadas de cartuchos e projéteis enferrujados das atrozes batalhas" (LLOSA, 2008, p. 5).

Vê-se, pela dada importância de se colocar em destaque as experiências e vivências relacionadas aos espaços e lugares pertencentes ao âmbito que circunda o ocorrido em Canudos, que a história ficcionalizada por Llosa evidencia certa preocupação por parte de seu autor a respeito do processo de reconstrução das imagens de um outro tempo. Tempo este, muitas vezes, rebuscado a partir de narrativas e relatos de moradores dessas localidades, que tiveram, de certa forma, à medida que histórias eram contadas por parentes e conhecidos, um contato mais próximo com o sucedido em Canudos, cerca de oito décadas depois. Com efeito, a intenção declarativa leva-nos a considerar que, assim como afirma Walther Benjamin, "a experiência que passa de pessoa a pessoa é a fonte a que recorrem todos os narradores" (BENJAMIN, 1987 p. 198), ou seja, as histórias marcadas pelo labirinto do anonimato.

O professor e escritor Antonio Candido (2006), em seu livro Literatura $e$ Sociedade, aponta para uma discussão acerca da estreita relação entre a literatura e a realidade social ao pensar o diálogo entre a obra de arte e a sociedade da qual ela é derivada. Com isso, ele evidencia a necessidade de se encarar a obra sem se esquecer do conjunto de fatores sociais que operam na formulação dela. Ele também argumenta que a produção literária é, de modo inerente, resultado de uma contextura formada por características sociais distintas, porém complementares. Beatriz Sarlo (2010), por exemplo, entende que a memória, tanto a coletiva como a individual, é pautada pela 
restauração e na reafirmação da subjetividade. Isto é, seus estudos se pautam nas memórias dos oprimidos e das massas, permitindo assim, através da oralidade, a sua explosão. De forma mais ampla, a autora também se refere à memória como uma possível matéria-prima dos sentimentos humanos.

Nesse sentido, é importante lembra que o conflito em Canudos foi motivado por uma série de fatores. Fosse no setor econômico com a crise latifundiária marcada por longos períodos de estiagem, fosse pelo caráter social segregacionista que dividia o litoral do sertão, a região, à época, encontrava-se em quase completo abandono, o qual impulsionou, talvez, a forte ligação com as disposições metafísicas. Sem dúvidas, historicamente, a humanidade é marcada por certas pulsões de esperança em crenças religiosas sempre que diante de catástrofes naturais ou sociais. Isso pode ser mais bem ilustrado se tomarmos como referência o tópico "Desastres e esperanças: dos flagelantes à devotio moderna, presente no livro História das crenças e das ideias religiosas [1976]" de Mircea Eliade. De acordo com o autor, por exemplo:

O século XIV caracteriza-se não apenas pelas grandes crises que abalaram a Igreja ocidental, como também por uma série de calamidades e de flagelos cósmicos: cometas, eclipses solares, inundações e, sobretudo a partir de 1347, a terrível epidemia de peste, a "Morte Negra". É com o propósito de comover Deus que se multiplicam as procissões dos flagelantes. Trata-se de um movimento popular que segue o trajeto característico: da devoção à heterodoxia (ELIADE, 2011, p. 195-196).

Ainda que, cinco séculos depois, a situação descrita nas páginas deste tratado de história das religiões nos faz perceber a estreita ligação com a realidade de crença tão forte em uma salvação de ordem divinatória por parte dos humildes habitantes do sertão, na virada do século XIX para o XX. Com seus flagelos do clima e da exclusão econômica-social existente, Canudos se torna o espaço exemplar de um lugar sagrado diante das reações cíclicas da miséria humana. No romance de Llosa, essa parte mais específica do hábito de tortura do próprio corpo pode ser revista pela descrição da vida de beatitude na figura do personagem Antonio Beatinho e seus sacrifícios, que, enquanto aguardava a volta do Conselheiro pelas suas terras, usava um cinto especial revestido por pregos para ferir a própria carne. Além disso, notoriamente, a figura messiânica é um dos primeiros emblemas que aparece no romance, como se pode constatar em uma das primeiras descrições do Conselheiro:

Usava sandálias de pastor e a túnica roxa que lhe caía sobre o corpo lembrava o hábito daqueles missionários que, vez por outra, visitavam as vilas do sertão 
batizando multidões de crianças e casando os pares amancebados. Era impossível saber sua idade, sua procedência, sua história, mas havia algo na sua expressão tranqüila, nos seus costumes frugais, na sua imperturbável seriedade que, antes mesmo de começar a dar conselhos, atraía as pessoas (LLOSA, 2008, p. 10).

Essa passagem descreve, em imagens, para além da relação com o sagrado, como era ou poderia ser o contato das gentes daqueles povoados naquela época com uma das personalidades mais intrigantes da nossa história, o Antônio Vicente Mendes Maciel, mais conhecido como Antônio Conselheiro. Nas linhas narradas, este homem aparece como aquele que chegava tão primeiramente e se dirigia à igreja - templo, espaço sagrado -, em geral entregue às ruínas, e por meio de rituais com rezas e comportamentos que o diferenciava dos outros sujeitos dali: "também outras rezas que ninguém tinha ouvido antes mas que, ao longo dos dias, dos meses, dos anos, as pessoas iriam memorizando" (LLOSA, 2008, p. 10).

A forma de interação, nesse caso, é fator decisivo, já que, quando estamos diante de um romance histórico, segundo Lukács (2011), não se trata de reviver pura e simplesmente o passado pelo fato de revivê-lo, mas sim no sentido de recriar o comportamento dos seres humanos que atuaram nos fatos que configuram este passado. Sendo assim, apesar da guerra ser o tema central proposto pelo romance de Llosa, é como se o movimento de ficcionalização das personagens exercesse um resgate do fato histórico a partir da tradição oral, com o relato de pessoas que viveram ou tiveram algum contato com aquela época, pondo em relevância, sobretudo, a descrição dos comportamentos e das razões que levaram os homens daquele corte temporal a passar por experiências tão traumáticas.

Pode-se dizer que, já em 1893, as relações dos habitantes de Canudos com o governo entraram em conflito quando os moradores queimaram documentos oficiais em um ato de rebeldia contra os altos impostos cobrados pela República, mesmo diante do total descaso e abandono. O que, claro, levou os governantes a taxar os cerca de 25 mil habitantes como fanáticos religiosos e rebeldes monarquistas de alto perigo e ameaça ao Estado, dando início assim aos desmontes armados. Metaforicamente, a narrativa faz referência a alguns anos que tiveram relativa importância no contexto de Canudos, tendo início desde 1896 passando por 1897/98 até o ano da virada 1899:

Em 1896 mil rebanhos correriam da praia para o sertão, e o mar viraria sertão e o sertão, mar. Em 1897 o deserto se cobriria de grama, pastores e rebanhos se misturariam e, a partir de então, haveria um único rebanho e um único pastor. 
Em 1898 os chapéus aumentariam e as cabeças diminuiriam, e em 1899 os rios ficariam vermelhos e um novo planeta cruzaria o espaço (LLOSA, 2008, p. 11).

Nesse fragmento, especificamente, pode-se notar o jogo dinâmico do foco narrativo ao lidar com os dois tipos de memórias, propostos por Jan Assmann (2008): a memória comunicativa e a memória cultural. Seja a primeira com lembranças cotidianas passadas através da oralidade, por essa razão tem um conteúdo prolixo e cambiante que pertence a um passado recente - as narrativas dos acontecimentos em Canudos em si -, seja a segunda que se constrói a partir de um passado longínquo que se relaciona com a história ancestral ou mítica, por exemplo, a velha lenda de que o sertão vai virar mar um dia embutido no nosso imaginário popular cultural. Logo, é importante lembrar, independentemente de qualquer coisa, a história, além de resgatar o passado do ponto de vista social, também é um processo que encontra paralelo em cada indivíduo e seus grupos por intermédio da memória; esta, por sua vez, age sobre aquilo que foi vivido.

Sabe-se que o ano de 1896 foi o primeiro ano do conflito; 1897 marca o percurso e término do conflito armado com a descoberta do cadáver de Antônio Conselheiro; em 1898, o pós-conflito e a denúncia social a partir dos números de morte; em 1899, o fim de um século para início de outro, uma nova formação paradigmática. Os "rebanhos que corriam da praia para o sertão" eram os soldados da primeira República, o "único rebanho" estaria para a representação da ideia de nação unificada que, inclusive, aparece de forma bem visível dentro do texto com a quebra da estrutura linear da narrativa por meio de uma imagem de uma notícia de jornal. É o que inicia o tópico II do capítulo Dois do romance, como pode ser visto da Foto 1 abaixo:

Imagem 1 - Detalhe da abertura do capítulo Dois de A guerra do fim do mundo, de Mario Vargas Llosa

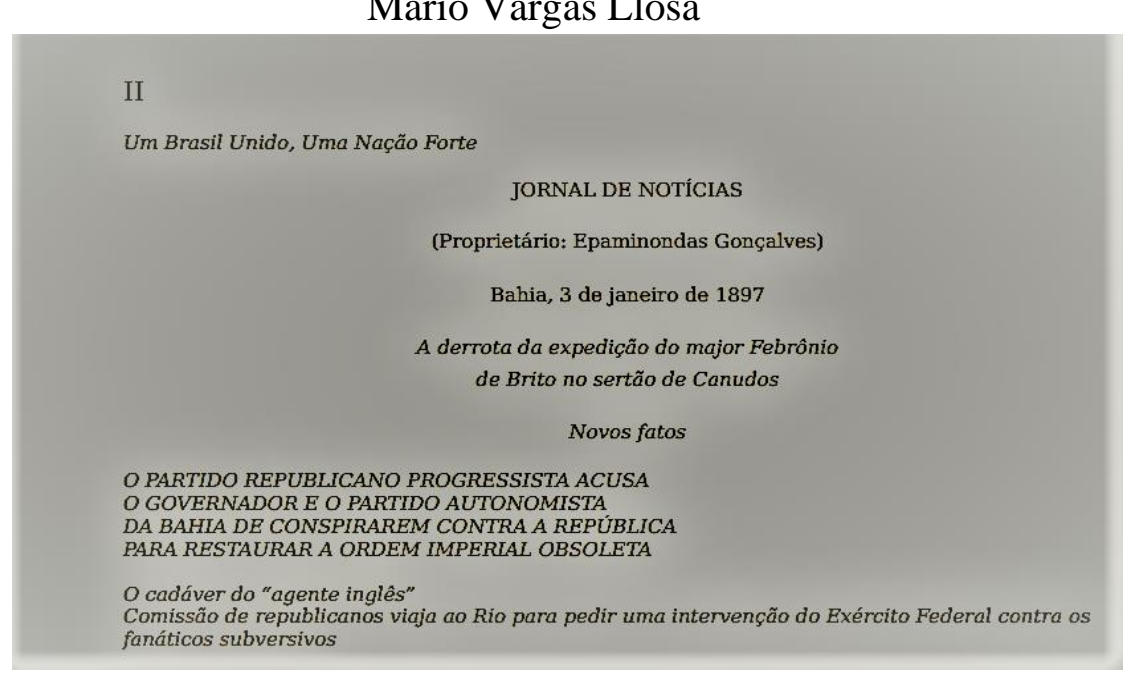

Fonte: (LLOSA, 2008, p. 68). 
Não à toa, nessa parte do romance, há uma quebra da narrativa, como já foi mencionado. Além de sabermos a forte ligação com o gênero notícia por parte do autor, que é jornalista, o ocorrido em Canudos também marca o início de uma outra realidade com os meios de comunicação, pois é a partir dos acontecimentos do sertão da Bahia que os gêneros jornalísticos ganham destaque e maior relevância naquele período, desde o âmbito nacional até o internacional. Ou seja, trocar a estrutura narrativa por uma espécie de ilustração com manchete, título auxiliar e um lide remonta os meios pelos quais as narrativas de cunho factual mais transitavam naquela época. Canudos era a notícia da época. É o que nos mostra a tese de doutorado em Comunicação e Cultura, da pesquisadora Lidiane Santos de Lima Pinheiro:

Foi durante a Campanha de Canudos que o Brasil testemunhou pela primeira vez uma cobertura diária de um acontecimento estritamente nacional, ao qual foi dada tamanha importância que jornalistas de diversos periódicos foram enviados à região como correspondentes (prática inaugurada ou intensificada a partir de então no Brasil), e os jornais que não o fizeram quase cotidianamente transcreviam reportagens sobre o evento, de outros órgãos de imprensa. (PINHEIRO, 2012, p. 17).

Certamente, Vargas Llosa apropriou-se desse discurso de caráter jornalístico para pôr em questão os lapsos fragmentários que a guerra de Canudos abrolhou das sucessivas investidas midiáticas dos seus ocorridos. Nesse caso, a noção de presente que a notícia traz é colocada sob suspense à medida que temos a consciência de que o discurso jornalístico também faz parte da constituição de uma memória promovida por inúmeras e distintas narrativas não menos imbuídas em uma interdiscursividade marcada pelo fator subjetivo. Assim, passado, presente e aquilo que se espera do futuro formam um ciclo, no qual os tempos se mesclam em uma outra possibilidade de leitura, que vê no tempo presente a impossibilidade das realidades palpáveis.

\section{A tessitura das personagens}

O professor Alfredo Bosi, em um depoimento apresentado no Colóquio Osman Lins: literatura, teatro e ensaio ocorrido nos dias 22, 23 e 24 de novembro de 2004, além de relatar a sua relação literária com o amigo e escritor Osman Lins, fala-nos sobre a experiência de ter sido "desenhado" personagem pelo olhar desse ficcionista pernambucano, que "muito malandramente chamou de 'A.B"' (BOSI, 2014, p. 175). Tal personagem aparece no romance $A$ rainha dos Cárceres da Grécia (1976) logo nas primeiras páginas. Esse recorte serve para nos inteirar da grandeza e complexidade que 
é o processo de tessitura das personagens dentro de qualquer texto de caráter ficcional. Ou seja, ironicamente ou não, Bosi nos fala sobre o perigo que é estar diante de um escritor de literatura, pois a qualquer momento qualquer um pode vir a ser transformado em uma personagem de ficção. Que as personagens partem senão dos perfis de pessoas reais ou imaginadas.

A propósito desse contexto e, também, o professor Antonio Candido, em $A$ personagem de ficção, afirma que "o enredo existe através das personagens; as personagens vivem no enredo. Enredo e personagem exprimem, ligados, os intuitos do romance, a visão da vida que decorre dêle, os significados e valores que os animam" (CANDIDO, 1970, p. 51). Modelarmente, no romance A guerra do fim do mundo de Vargas Llosa, o enredo é constituído sob um movimento delicado de espelhamento de imagens em pessoas reais que passaram pelo artifício da ficcionalização. Nitidamente, as personagens desenhadas por Llosa funcionam como meios que possibilitam a saída dos indivíduos do plano real para o plano imaginário, de sujeitos reais para sujeitos criados.

Nessa perspectiva, Antonio conselheiro, o Barão de Canabrava, o republicano Epaminondas Gonçalves, o jornalista míope - que supostamente seria a própria figura do escritor Euclides da Cunha, Maria Quadrado, João Abade, o Leão de Natuba, Antonio Beatinho, Galileo Gall e muitos outros personagens fermentam a massa do enredo que tece o romance tematicamente sobre a guerra de Canudos. Na realidade, o que promoveu o conflito ocorrido em Canudos foi a força de revolta de uma gente marcada pela violência e miséria, pessoas reais, diante da fragmentada e limitada condição humana, foram as personalidades humanas que deram cria às personagens fictícias. Assim, à medida que são transplantados para o ambiente ficcional diante de uma elaboração estética da linguagem, possibilitam a transposição dos fatos históricos narrados para um aspecto sensível, ao envolver pouco a pouco os leitores em uma teia de emoções a transbordar a própria imagem da realidade.

Por essa razão, para uma melhor abordagem desse caráter criativo da personagem de ficção, vejamos com mais detalhe algumas das personagens do romance de Llosa. O Conselheiro, por exemplo, é uma espécie de personagem central que constitui a estrutura narrativa do romance, já que, de uma maneira ou de outra, muitos personagens acabam envolvidas na sua rede de tramas e ações que conduzem o enredo. Um traço comum entre todas as personagens que aparecem ligados à figura messiânica, que era o Conselheiro é a questão da revolta e da transformação pessoal. Grosso modo, 
todos que cruzavam o seu caminho passavam por perturbações existenciais, pois de algum modo o Conselheiro estava sempre "diante de quem sempre aparecia turbado e abalado internamente" (LLOSA, 2008, p. 81).

Como em um movimento cíclico, pouco a pouco, a narrativa descreve essas várias "personalidades" reais/fictícias que se viam interligadas ao Conselheiro frente à necessidade e ao desespero de se agarrarem a algo que desse sentido às próprias vidas. A imagem que se constrói desse homem é a de um chefe, um guia, um provedor de caminhos aos "desgarrados" e que trazia, acima de tudo, o poder da palavra e do convencimento em uma terra em que já não se dava para acreditar mais em nada, nem na própria força da natureza. Claramente, Llosa deixa escapar algumas visões simbólicas acerca de determinadas correntes de pensamentos políticos pela feitura descritiva de certas personagens, sobretudo, as das ideias de uma liderança comunista do conselheiro, vistas pelos devaneios da figura intrigante de Galileo Gall, ou diante do perfil de comportamento de toda uma comunidade guiada por Antonio Conselheiro:

O Conselheiro teria convencido os jagunços de que é pecado - acreditem considerar como próprio qualquer bem movente ou semovente. As casas, os cultivos, os animais, tudo pertence à comunidade, tudo é de todos e de ninguém. O Conselheiro os convenceu de que quanto mais coisas a pessoa possuir, menos possibilidades tem de estar entre os favorecidos no dia do Juízo Final (LLOSA, 2008, p. 30).

Em um movimento quase que repetitivo, a narração descritiva das personagens que vão entrando na trama desenvolvida pelo enredo começa sempre pela vida da personagem ainda quando criança acerca de algum detalhe significativo na vida desta, seja por um ponto traumático singular de suas vidas, seja por uma miséria sofrida de forma coletiva. Todas as personagens aparecem gradualmente em suas composições, sendo que cortadas por tópicos que fragmentam a linearidade da narrativa, com cenas das linhas de vida de cada uma delas até um entrecruzar de histórias. O que há, acima de qualquer coisa, é a tentativa de colocar em destaque a figura humana, o lado humano do fato histórico por aqueles que o vivenciaram em sua linha de frente, marcados por toda aridez que a vida os tinha reservado. É o que se pode ver nas tessituras de certas personagens como a de João Abade que antes da conversão era o cangaceiro João Satã:

Suas primeiras lembranças, que também seriam as melhores e as que voltariam com mais pontualidade, não eram de sua mãe, que o abandonou para ir atrás de um sargento da Guarda Nacional que passou por Custódia perseguindo cangaceiros à frente de uma volante, nem do pai, que jamais conheceu, nem dos tios que o acolheram e criaram — Zé Faustino e dona Ângela —, nem dos trinta 
barracos e das ruas ressecadas de Custódia, e sim dos cantadores ambulantes (LLOSA, 2008, p. 34).

Nota-se que as lembranças dessa personagem são marcadas pela realidade de abandono desde o início da vida - a figura materna que foge com um militar, a imagem do pai nem sequer construída - , a ponto de suas melhores lembranças estarem atreladas a sujeitos desconhecidos, porém poéticos, pela expressão dos cantadores de Custódia. Eis aqui uma possível demonstração simbólica do abandono sofrido por toda aquela gente por parte do estado, se pensarmos de forma mais ampla a questão da revolta. Nessa parte da narrativa, João Abade quando era apenas João, torna-se o João Satã motivado por uma profunda revolta depois que um soldado do Estado, caçador de cangaceiros, mata friamente os seus tios, Zé Faustino e dona Ângela, únicos indivíduos por quem havia nutrido afeto ainda quando era João. Outra personagem, João, que também é uma figura marcante na narrativa é o João Grande:

João Grande nasceu perto do mar, num engenho do Recôncavo, cujo dono, o senhor Adalberto de Gumúcio, era grande apreciador de cavalos. Ele se gabava de possuir os alazões mais briosos e as éguas de tornozelos mais finos da Bahia e de ter obtido esses espécimes, sem necessidade de sementais ingleses, mediante sábios acasalamentos que ele mesmo controlava. Gabava-se menos (em público) de ter feito a mesma coisa com os escravos da senzala, para não levantar a poeira dos conflitos que tivera com a Igreja e com o próprio barão de Canabrava, mas na verdade agia com os escravos da mesma maneira que com os cavalos (LLOSA, 2008, p. 20).

Assim como o João anterior, João Grande também traz na sua essência de personagem a marca do abandono por meio da "desfiliação", quando é pensado desde a sua origem animalizada, já que ele se trata do resultado de uma das experiências, do dito senhor de engenho Adalberto de Gumúcio, assim como os cavalos. Quando ainda criança, é retirado do seio materno da escrava que o parira e dado de presente, assim como um objeto, à sinhazinha da casa grande, Adelinha Isabel de Gumúcio, irmã do senhor de engenho, que passa a vida a tentar enquadrar em suas regras e caprichos o menino de traços e porte grosseiros. O ápice de expressão de revolta colocado pela personagem do João Grande é a morte fria e calculada de Adelinha pelas mãos dele.

Desse modo, o foco narrativo nos leva a perceber que há sempre uma causa motivadora que provoca a reação de revolta desses indivíduos, que pertencem à linha de frente que encabeça a dita guerra de Canudos. Outra passagem também bastante marcante dentro dessa ideia de composição das personagens é a Maria Quadrado, que traz uma história sofrida repleta de todo tipo de violência, sobretudo a sexual, com 
sucessivos atos de estupros realizados, brutalmente, contra ela. $\mathrm{O}$ perfil dessa personagem se desenvolve sobre o signo do sacrifício, até mesmo com símbolo metafórico do próprio Jesus, que carregou a cruz pelo caminho do Calvário com destino ao seu crucifixo. Como se pode verificar na seguinte passagem narrada: “Apareceu em uma madrugada sem chuva, em cima de um morro no caminho de Quijingue, arrastando uma cruz de madeira" (LLOSA, 2008, p. 26). Também essa personagem é vista pelo veio da sensibilidade da revolta, da insatisfação com o mundo e os homens cruéis pertencentes a ele.

Entende-se, portanto, que cada uma das personagens, a seu modo e figuração, são delineadas por um perfil único, mas que ao mesmo tempo guardam em si uma unidade de conservação: o sofrimento e a miséria da condição humana. Não é à toa que Llosa aponta para o caráter mais humano possível dessas personagens, inclusive, até mesmo os atos de perversão e absoluta brutalidade, do que é ser demasiadamente humano. Sem dúvidas, não se trata apenas de lidar com a descrição dessas personagens, reais ou não, e que tomam conta da edificação da narrativa, mas sim de subverter a ideia de tempo e espaço em pessoas, dotadas de toda subjetividade que se pode ter na vida. Por fim, pode-se dizer que o romance A guerra do fim do mundo não é, necessariamente, sobre a guerra de Canudos, ele é sobre as personalidades que enfrentaram essa história e todos os seus conflitos, armados, psicológicos, físicos, marcados por toda força de violência.

\section{Referências}

ASSMANN, Jan. Communicative and cultural memory. In: ERLL, Astrid; NÜNNING, Ansgar (ed.). Cultural memory studies: an international and interdisciplinary handbook. Berlin; New York: De Gruyter, 2008. p. 109-118. Disponível em: http://revista.historiaoral.org.br/index.php?journal=rho\&page=article\&op=view\&path $\%$ 5B $\% 5 \mathrm{D}=642 \&$ path $\% 5 \mathrm{~B} \% 5 \mathrm{D}=$ pdf. Acesso em: 25 out. 2020.

BENJAMIN, Walter. O narrador: considerações sobre a obra de Nikolai Leskov. In: BENJAMIN, Walter. Magia e técnica, arte e política: ensaios sobre literatura e história da cultura. São Paulo: Brasiliense, 1987. p. 197-221.

BOSI, Alfredo. O Osman Lins que conheci. Eutomia, Recife, v. 1, n. 13, p. 172-176, jul. 2014.

Disponível

em: https://periodicos.ufpe.br/revistas/EUTOMIA/article/view/630/458. Acesso em: 04 nov. 2020.

BURKE, Peter (org.). A Escrita da História: novas perspectivas. Trad. Magda Lopes. São Paulo: Editora Unesp, 1992. 
CANDIDO, Antonio. Literatura e sociedade. Rio de Janeiro: Ouro sobre Azul, 2006.

CANDIDO, Antonio; GOMES, Paulo Emílio Salles; PRADO, Décio de Almeida; ROSENFELD, Anatol. A personagem de ficção. São Paulo: Perspectiva, 1970.

ELIADE, Mircea. História das crenças e das ideias religiosas: de Maomé à Idade das Reformas. V. 3. Rio de Janeiro: Zahar, 2011.

ESTEVES, Antonio R. Considerações sobre o romance histórico (no Brasil, no limiar do século XXI). Revista de Literatura, História e Memória, Cascavel, v. 4, n. 4, p. 5466, 2008.

LE GOFF, Jacques. História e memória. Campinas: Editora da UNICAMP, 1990.

LUKÁCS, György. O romance histórico. São Paulo: Boitempo, 2011.

MENTON, Seymour. La nueva novela histórica de la América Latina, 1979-1992. México: Fondo de Cultura Económica, 1993.

NORA, Pierre. Entre memória e história: a problemática dos lugares. Proj. Histórias, São Paulo, v. 10, p. 7-28, dez. 1993. Disponível em: https://revistas.pucsp.br/index.php/revph/article/view/12101/8763. Acesso em: 15 out. 2020.

PINHEIRO, Lidiane Santos de Lima. A construção do acontecimento histórico: o discurso do jornal $\mathrm{O}$ Estado de S. Paulo sobre a guerra de Canudos e sobre as comemorações do seu centenário. Tese (Doutorado em Comunicação e Cultura Contemporâneas), Universidade Federal da Bahia, Salvador, BA, 2012. Disponível em: https://repositorio.ufba.br/ri/handle/ri/5970. Acesso em: 03 nov. 2020.

SARLO, Beatriz. Tempo passado: cultura da memória e guinada subjetiva. São Paulo: Companhia das Letras, 2007.

VARGAS LLOSA, Mario. A guerra do fim do mundo. Rio de Janeiro: Alfagara, 2008.

WHITE, Hayden. O texto histórico como artefato literário. In: WHITE, Hayden. Trópicos do discurso: ensaios sobre a crítica da cultura. São Paulo: Editora da Universidade de São Paulo, 2001, p. 97-118.

Artigo recebido em 29 de maio de 2021. Aprovado em 18 de agosto de 2021. 